\section{Surface Topography, Gloss and Flexural Strength of Pressable Ceramic After Finishing-Polishing Protocols}

\author{
Fernanda P. Silva ${ }^{1,2} \mathbb{D}$, Ana L. R. Vilela ${ }^{1} \mathbb{D}$, Matheus M. G. Almeida ${ }^{1}$, André
}

R. F. Oliveira ${ }^{\mathbb{D}}$, Luís H. A. Raposo ${ }^{4} \mathbb{D}$, Murilo S. Menezes ${ }^{1}{ }^{(\mathbb{D}}$

\author{
'Department of Operative Dentistry \\ and Dental Materials, School of \\ Dentistry, UFU - Universidade Federal \\ de Uberlândia, Uberlândia, MG, Brazil \\ ${ }^{2}$ Department of Dentistry, School \\ of Dentistry, UniRV- University of \\ Rio Verde, Rio Verde, GO, Brazil \\ ${ }^{3}$ School of Mechanical Engineering, \\ UFU - Universidade Federal de \\ Uberlândia, Uberlândia, MG, Brazil \\ ${ }^{4}$ Department of Occlusion, Fixed \\ Prosthodontics and Dental \\ Materials, School of Dentistry, \\ UFU - Universidade Federal de \\ Uberlândia, Uberlândia, MG, Brazil
}

Correspondence: Dr. Murilo de Sousa Menezes, Av. Pará, 1720, Bloco 4LA, Sala 42, 38405-320, Uberlândia, MG, Brasil. Tel: +55-34-3225-8106. e-mail: murilosmenezes@yahoo.com.br

Key-Words: ceramics, roughness, surface, polishing.

\section{Introduction}

Dental ceramics are currently one of the most popular restorative materials because of their natural and esthetic appearance, low heat conduction, good mechanical properties and wear resistance (1). These materials have been extensively used over metallic structures or in allceramic restorations like inlays, onlays, veneers and full crowns (2).

Ceramic restorations are commonly fabricated by dental laboratories using different techniques, such as CAD/CAM and press-over. In the heat pressing technique, a final contour wax-up can be made on the sintered zirconia framework and invested, burned out, and pressed with flourapatite pressable ceramic. This technique has the advantages of being faster, with detailed and esthetic reproduction of the wax-up, presenting less distortion, increased marginal accuracy, and being less costly $(3,4)$. During the restoration fabrication process, a final glaze surface is created in the restoration with an oven firing process, by natural or additive procedures (5). This process results in restorations with smooth and biocompatible surface (6), which can improve the flexural strength and preserves surface gloss (7). However, despite the careful procedures taken by the practitioner and dental technician to produce indirect restorations, it is not uncommon to perform clinical adjustments in the glazed ceramic surface using diamond burs or other instruments for correcting occlusal contacts and/or inadequate contours (8). After performing clinical adjustments, surface roughness of ceramic restorations will predictably increase (8). The rough surfaces can cause biofilm accumulation (8), and may lead to severe wearing of opposite teeth (9). Furthermore rough or irregular ceramic surfaces may cause stress concentration and initiate cracking propagation, resulting in premature failure of the restoration (10).

Hence, all adjusted ceramic restorations should be submitted to a further polishing protocol since surface quality is essential for clinical success (11). Finishing and polishing procedures are important for reducing the roughness of adjusted ceramic surfaces $(1,2)$, preventing discoloration of roughened areas in order to maintain the natural appearance $(1,7)$, as the gloss of the ceramic surface is commonly restored (7). Currently, several systems for finishing-polishing of dental ceramics are available in the market. These systems can be effective in producing a regular surface and save working time after small ceramic adjustments, since it is not necessary to return the restorations to the dental laboratory (2). 
Thus, the aim of this study was to evaluate the effect of different surface treatments on the surface roughness, gloss, morphology and biaxial flexural strength of a pressable fluorapatite glass ceramic. The null hypothesis tested was that the different surface treatments would not influence the physical properties of the pressable ceramic as compared to ceramic surfaces obtained with laboratory glaze procedures.

\section{Material and Methods}

\section{Specimen Preparation}

Thirty pressable fluorapatite glass ceramic discs, $12 \mathrm{~mm}$ in diameter and $1 \mathrm{~mm}$ thick, were fabricated according to the manufacturer's recommendations (IPS e.max ZirPress, Ivoclar Vivadent, Schaan, Liechtenstein). For preparing the specimens, standard disc-shaped acrylic resin patterns (Duralay, Reliance Dental Manufacturing, Chicago, IL, USA) were confectioned $(n=5)$. The resin discs were polished with silicon carbide abrasive papers (\#180, 320,600, Norton, Campinas, SP, Brazil) until the correct thickness was obtained. A digital caliper (Mitutoyo, Santo Amaro, SP, Brazil) was used to ensure consistency in the dimensions of the resin patterns.

The specimens in acrylic resin were invested in a phosphate-based investment material (IPS PressVest, Ivoclar Vivadent). Resin patterns were eliminated in a proper furnace and prefabricated pressable fluorapatite glass ceramic ingots were then pressed using the lostwax technique. The pressing process was carried out in a press furnace (EP3010, Ivoclar Vivadent) according to the manufacturer's instructions. After divesting, specimens were polished with silicon carbide abrasive papers (\#600) followed by ultrasonic cleaning in distilled water for 10 min. Sequentially, all specimens were polished with abrasive rubber discs and submitted to glazing firing using glaze paste (e.max Glaze Paste, Ivoclar Vivadent). This process was performed with Ivoclar preset programming P310 furnace protocol (Ivoclar Vivadent) (initial temperature $403{ }^{\circ} \mathrm{C}$; temperature rise $60 \% \mathrm{~min}$; final glazing temperature 770 ${ }^{\circ} \mathrm{C}$ for $90 \mathrm{~s}$; vacuum initiated at $450{ }^{\circ} \mathrm{C}$ and released at 769 $\left.{ }^{\circ} \mathrm{C}\right)$. Ten minutes after opening the furnace, the discs were removed, and bench cooled.

\section{Groups}

The specimens were randomly divided into 5 groups $(n=6)$ according to surface treatments: CT- control group (glaze); DA- surface abrasion with fine grit diamond bur (\#4137F, KG Sorensen, Barueri, SP, Brazil); DG- abrasion with fine grit diamond bur (\#4137F) followed by application of a new glaze layer; DP: abrasion with fine grit diamond bur (\#4137F), followed by polishing with felt disk (DHPro; Paranaguá, PR, Brazil) impregnated with fine-grit diamond paste (Diamond Excel, KG Sorensen); DK- abrasion with fine grit diamond bur (\#4137F), followed by sequential polishing with silicon carbide abrasive instruments (coarse, medium, and fine grit), goat hair brush and cotton wheel (DHPro). One trained operator subjected all the specimens from each group to the respective finishing-polishing protocols for $30 \mathrm{~s}$ using slow-speed hand piece (Kavo Kerr, Biberach, Germany) to simulate clinical procedures. Each polisher was used with the same slow-speed hand piece maintaining uniform and intermittent pressure for all groups. The equipment was set to 9,000 rpm. After the surface treatments, all specimens were ultrasonically cleaned in distilled water for $10 \mathrm{~min}$.

\section{Surface Roughness}

For analyzing the surface roughness of the specimens, the arithmetic mean (Ra- average surface roughness) was assessed with a digital profilometer (Surftest SJ-410; Mitutoyo Corp, Tokyo, Japan). For measuring the roughness profile value in micrometers $(\mu \mathrm{m})$, a diamond stylus with $5 \mu \mathrm{m}$ tip radius was moved across the surface under a constant load of $4 \mathrm{mN}$ with a speed of $0.25 \mathrm{~mm} / \mathrm{s}$ and a range of $0.8 \mathrm{~mm}$. Three traces were recorded for each specimen at three different positions (parallel, perpendicular, and oblique), resulting in nine tracings per specimen. The mean surface roughness was then calculated for each specimen.

An atomic force microscope (AFM,XE-70;ParkSystemsInc. Santa Clara, CA, USA) operated in no contact mode, was used to obtain quantitative and qualitative evaluation of the specimens. In no contact mode, the force between the AFM tip and the specimen surface was kept constant by the microscope feedback system, while the specimen surface was scanned beneath the AFM tip and the vertical piezoelectric ceramic movement was recorded. Images with $512 \times 512$ pixels were acquired with a scan size of $20 \mu \mathrm{m}$ x $20 \mu \mathrm{m}$ at a scan rate of $1.00 \mathrm{~Hz}$. An NP-type V-shape Si3N4 cantilever with a tip radius of approximately $10 \mathrm{~nm}$ was used. The AFM obtained a 3-dimensional image of the surface of the specimen. Two different areas were measured in each specimen at different regions, all located in the center of the object. The surface roughness parameters Ra were then calculated in both slow and fast scanning directions using the built-in functions of the Mountains map 3.0.0.1 software. Means and standard deviation of surface roughness were then determined.

\section{Spectrophotometric Reflectance}

The reflectance values of the specimens were measured using a spectrophotometer (USB4000, Ocean Optics, Winter Park, FL, USA) associated with an optical fiber cable. The specimens were positioned in a device platform and a light bean was focused over the ceramic surface to allow 
measuring the intensity of reflected light. For each specimen four measurements were conducted. Data were recorded on Origin 8.0 software (Origin 8.0, OriginLab Corporation, Northampton, MA, USA).

\section{Biaxial Flexural Strength}

The biaxial flexural strength of the discs was checked with a tension-compression device (DL2000, EMIC, São José dos Pinhais, PR, Brazil) at a crosshead-speed of 0.5 $\mathrm{mm} / \mathrm{min}$. The specimens were orientated so the finishedpolished surfaces were subjected to compressive stressing and tested according to ISO 6872 (12). To support the specimens, 3 hardened steel balls $(3.2 \mathrm{~mm}$ in diameter) were placed at an angle of 120 degrees relative to each other. The diameter of the support circle was $10 \mathrm{~mm}$. Each specimen was centrally located on the supports and the loading was applied at the center of the glazed surfaces of the specimens. A flat piston $(1.4 \pm 0.2 \mathrm{~mm}$ in diameter) was used during loading until fracture of the specimens. At this point, the fracture load was recorded.

\section{Scanning Electron Microscopy Analysis}

Representative specimens of each group were selected

SCD050, Leica Microsystems, Wetzlar, Germany) at 15.0 $\mathrm{kV}$, after sputter-coating with a thin film of gold. The SEM photomicrographs were taken with $100 \times$ magnification for qualitative analysis of the specimens.

\section{Statistical Analysis}

The data were analyzed using the SigmaStat v.3.5 statistical software package (Systat Software Inc., Chicago, IL, USA). The surface roughness, spectrophotometric reflectance and biaxial flexural strength data were individually submitted to one-way analysis of variance followed by Tukey's test $(\alpha=0.05)$, since data presented normal distribution based on the Shapiro-Wilk test ( $p>0.05)$.

\section{Results}

\section{Surface Roughness}

The results for the surface roughness are summarized in Table 1. For the perfilometry, significant differences were found among the surface roughness of the experimental groups $(p<0.001)$. Specimens from DK group presented the lowest mean surface roughness values and DA group presented the highest mean surface roughness.

The AFM analysis showed that the groups submitted to the glazing process, CT and DG, and to the sequential finishing-polishing protocol (DK) presented the lower mean surface roughness values $(p<0.001)$ (Table I). The group abraded with fine grit diamond bur only (DA) followed by polishing with fine-grit diamond paste (DP) showed the highest mean surface roughness. The AFM images obtained from the specimens corroborate with the measured roughness values (Fig. 1 A-E), showing the different surface roughness characteristics for all the surface treatments.

\section{Spectrophotometric Reflectance}

One-way analysis of variance identified significant differences in the gloss verified among the experimental groups $(p<0.001)$. The DA and DP groups presented the lowest gloss values. DK and DG groups showed the highest gloss values. The CT group exhibited intermediary gloss values, not differing statistically from the other experimental groups.

\section{Biaxial Flexural Strength \\ One-way ANOVA showed the surface treatments had no significant effect on the biaxial flexural strength of the groups ( $p=0.274)$, which showed the following mean strength values (MPa): CT (100.6 \pm 17.72$), \mathrm{DA}(101.5 \pm 19.34)$, DG (124.1 \pm 17.84$), D P(116.2 \pm 10.51)$ and DK (119.6 \pm 32.17$)$.}

\section{SEM Analysis}

SEM analysis confirmed the roughness findings, with DG and DK groups exhibiting a morphological pattern similar to that of CT group with a smoother surface (Fig. $2 \mathrm{~A}, 2 \mathrm{C}$ and $2 \mathrm{E})$. The $\mathrm{DA}$ and DP groups exhibited variable degrees of surface irregularities (Fig. 2B and 2D). The surface irregularities and voids were reduced by sequential polishing with abrasive silicon carbide points (DK), even though,
Table 1. Means values and standard deviation ( \pm ) for the experimental conditions

\begin{tabular}{lcccc}
\hline Group & \multicolumn{2}{c}{ Surface roughness - Ra $(\mu \mathrm{m})$} & $\begin{array}{c}\text { Gloss values } \\
\text { (Gloss } \\
\text { Unit- GU) }\end{array}$ & $\begin{array}{c}\text { Biaxial } \\
\text { flexural } \\
\text { strength } \\
(\mathrm{MPa})\end{array}$ \\
\hline CT & $0.83 \pm 0.12^{\mathrm{b}}$ & $0.10 \pm 0.05^{\mathrm{a}}$ & $3356.8 \pm 3455^{\text {ab }}$ & $100.6 \pm 17.72^{\mathrm{a}}$ \\
DA & $1.53 \pm 0.13^{\mathrm{d}}$ & $0.27 \pm 0.12^{\mathrm{b}}$ & $3349.7 \pm 3325^{\mathrm{b}}$ & $101.5 \pm 19.34^{\mathrm{a}}$ \\
DG & $0.84 \pm 0.06^{\mathrm{b}}$ & $0.12 \pm 0.10^{\mathrm{a}}$ & $3360.8 \pm 5336^{\mathrm{a}}$ & $124.1 \pm 17.84^{\mathrm{a}}$ \\
DP & $1.17 \pm 0.10^{\mathrm{c}}$ & $0.30 \pm 0.14^{\mathrm{b}}$ & $3350.7 \pm 4771^{\mathrm{b}}$ & $116.2 \pm 10.51^{\mathrm{a}}$ \\
DK & $0.38 \pm 0.51^{\mathrm{a}}$ & $0.09 \pm 0.02^{\mathrm{a}}$ & $3364.7 \pm 5893^{\mathrm{a}}$ & $119.6 \pm 32.17^{\mathrm{a}}$ \\
\hline
\end{tabular}

CT: control (glaze); DA: fine grit diamond bur; DG: DA + new glaze layer; DP: DA + felt disk with fine grit diamond paste; DK: DA+ sequential polishing with silicon abrasive instruments, goat hairbrush and cotton wheel. *Distinct lowercase letters indicate statistically significant differences among groups in columns $(\mathrm{p}<0.05)$. Means (95\% confidence intervals) for the different tested response variables. 
some voids still persisted after using this protocol (Fig. 2E).

\section{Discussion}

The null hypothesis was rejected, since the different surface treatments tested affected the physical properties of the pressable fluorapatite glass ceramic evaluated as compared to ceramic surfaces obtained with laboratory glaze procedures.

The wide application of dental ceramics in contemporary restorative dentistry has created numerous concerns for the clinicians regarding the correct protocols for finishing and polishing these restorations when clinical adjustments are needed. As seen, ceramic restorations needs suitable surface treatments procedures to achieve smooth surfaces, avoiding biofilm accumulation, crack propagation (8), decrease in the porcelain strength (10), besides reducing the wear of the opposing natural teeth as well as restorative surfaces (9). The application of a glass ceramic layer by the glazing process is considered the gold standard after performing adjustments in ceramic restorations (6); however, it has some disadvantages, such as, additional time due to the laboratory processing and the impossibility to be made after luting procedures (13).
The surface roughness and gloss of dental ceramics varies according to the methods and materials/instruments used during laboratory manufacturing. Attempting to reestablish surface smoothness to roughened ceramics after clinical adjustments, several chairside ceramic finishing/ polishing systems are available nowadays, although there is still controversy about their effectiveness in literature. The finishing and polishing protocol used for the DK group presented the best performance among all protocols, with similar results to the CT group. On the other hand, as one would expect, the group in which only finishing with fine grit diamond burs was carried out, showed the worst performance among all the experimental groups. This fact is particularly important to aware clinicians when performing chairside adjustments of glazed ceramic restorations before or after luting procedures, since special attention should be given for recovering surface characteristics similar to laboratory glazed or polished restorations.

To fully characterize the surface of pressable ceramic after using different surface treatments, a multimatic approach was employed. A perfilometer and atomic force microscope (AFM) were used to measure the roughness of the ceramic sufaces. The SEM and AFM techniques were
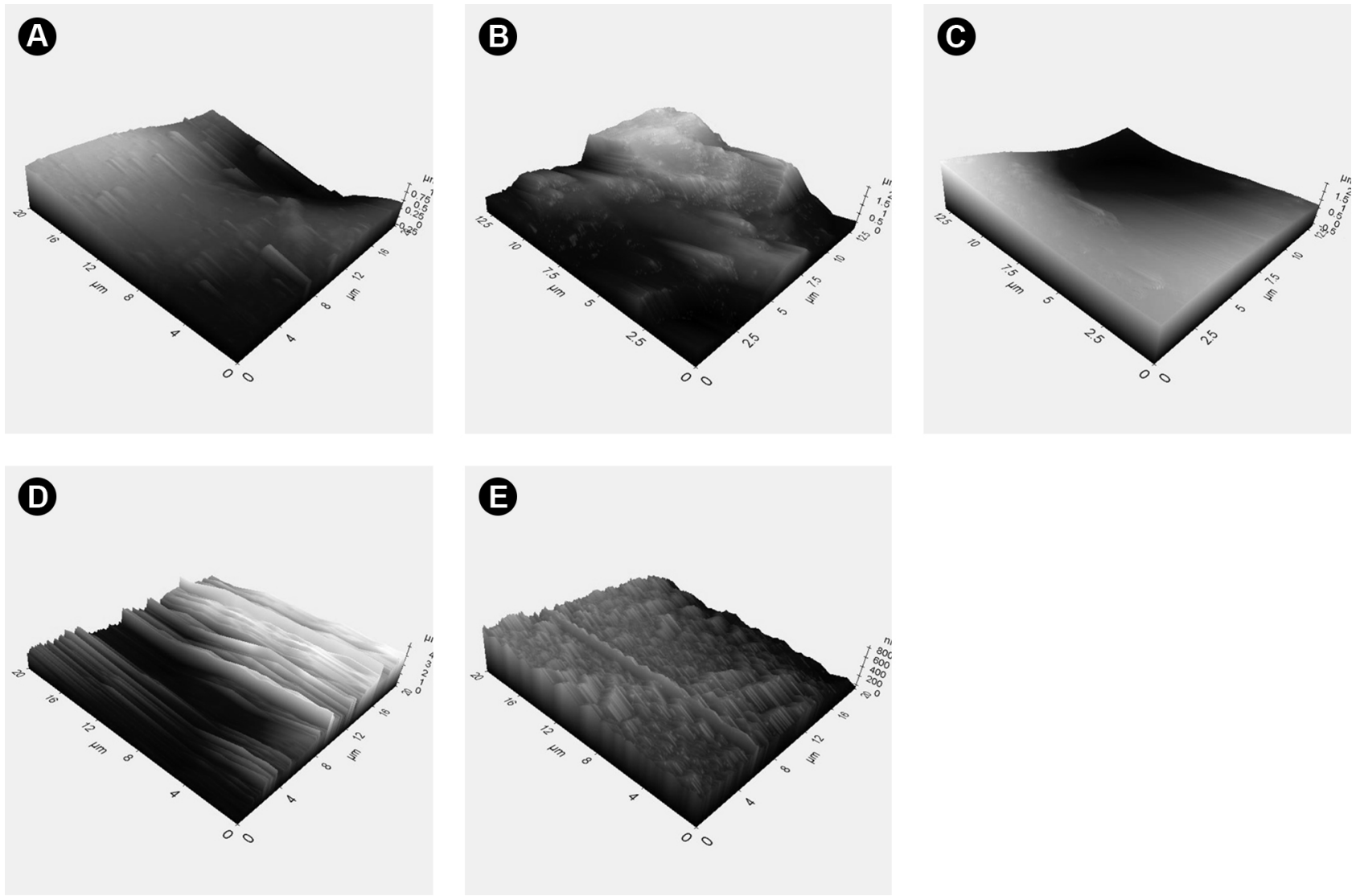

Figure 1. Representative AFM images of the topographic profiles at the ceramic surfaces of each experimental group: A: CT- control group (glaze); B: DA- fine grit diamond bur; C: DG- fine grit diamond bur + new glaze layer; D: DP- fine grit diamond bur + felt disk with fine grit diamond paste; E: DK- fine grit diamond bur + sequential polishing with silicon abrasive instruments, goat hair brush and cotton wheel. 
also employed to qualitatively evaluate the morphology and surface texture of the specimens. In the current study, no contact mode was used in the AFM to evaluate the surface roughness of ceramics as this approach has had several advantages when compared to other methods (14). The resolution of an optical light sensor is considerably higher than the mechanical pen used in contact scanners (15). Thus, the roughness values obtained using this technique are more precise, especially when evaluating very smooth surfaces such those of dental ceramics after finishing/ polishing procedures. In addition, non-contact acquisition mode for assessing roughness avoids surface damage that could be caused by a contact mechanical sensor, what could produce biased results (15). Since several authors found significant differences between the roughness values obtained using these two methodologies (14), direct comparison of the Ra values of the present study with the reports of other studies, as well as the reported threshold, must be conducted with caution.

The assessment of surface roughness with perfilometry and AFM was calculated by using the Ra parameter. The results showed that the DK group presented the lower surface roughness. These results are in accordance with \& previous studies $(1,16,17)$ which found similar roughness $\Xi$ values between glass ceramics submitted to glaze or sequential polishing with silicon carbide abrasive 2. instruments $(2,14,18)$. The DK group specimens have been submitted to sequential finishing/polishing with abrasive silicon carbide points with coarse, medium and fine grit, associated to goat hairbrush and cotton wheel, what may explain the findings of the present study. The abrasives particles of the silicon carbide points are hard enough to remove the irregularities from the ceramic surfaces (16), and final polishing with extremely fine abrasive materials are capable to reduce roughness (18). The CT and DG groups showed satisfactory results in the AFM analysis as the glaze procedures obliterates the irregularities present at the ceramic surface, improving surface smoothness (7).

The size of abrasive particles has a fundamental role in the resulting topographic characteristics of ceramic materials submitted to finishing/polishing protocols with different instruments. However, in this study, the experimental group submitted to finishing with diamond paste (DP) containing only homogeneous particle size, has not shown satisfactory surface roughness compared to CT group. This fact, can be explained because the polishing paste cannot promote an efficient polishing when used alone, showing that these materials needs to be associated to other polishing systems for dental ceramics (16). The DA group presented the highest surface roughness, showing that ceramic adjustments performed only with diamond points may cause grooves and gaps on the ceramic surface. These surface irregularities must be polished after the adjustment procedures in order to reduce the risk of crack propagation on the ceramic surface.

The SEM images confirmed the results found in the
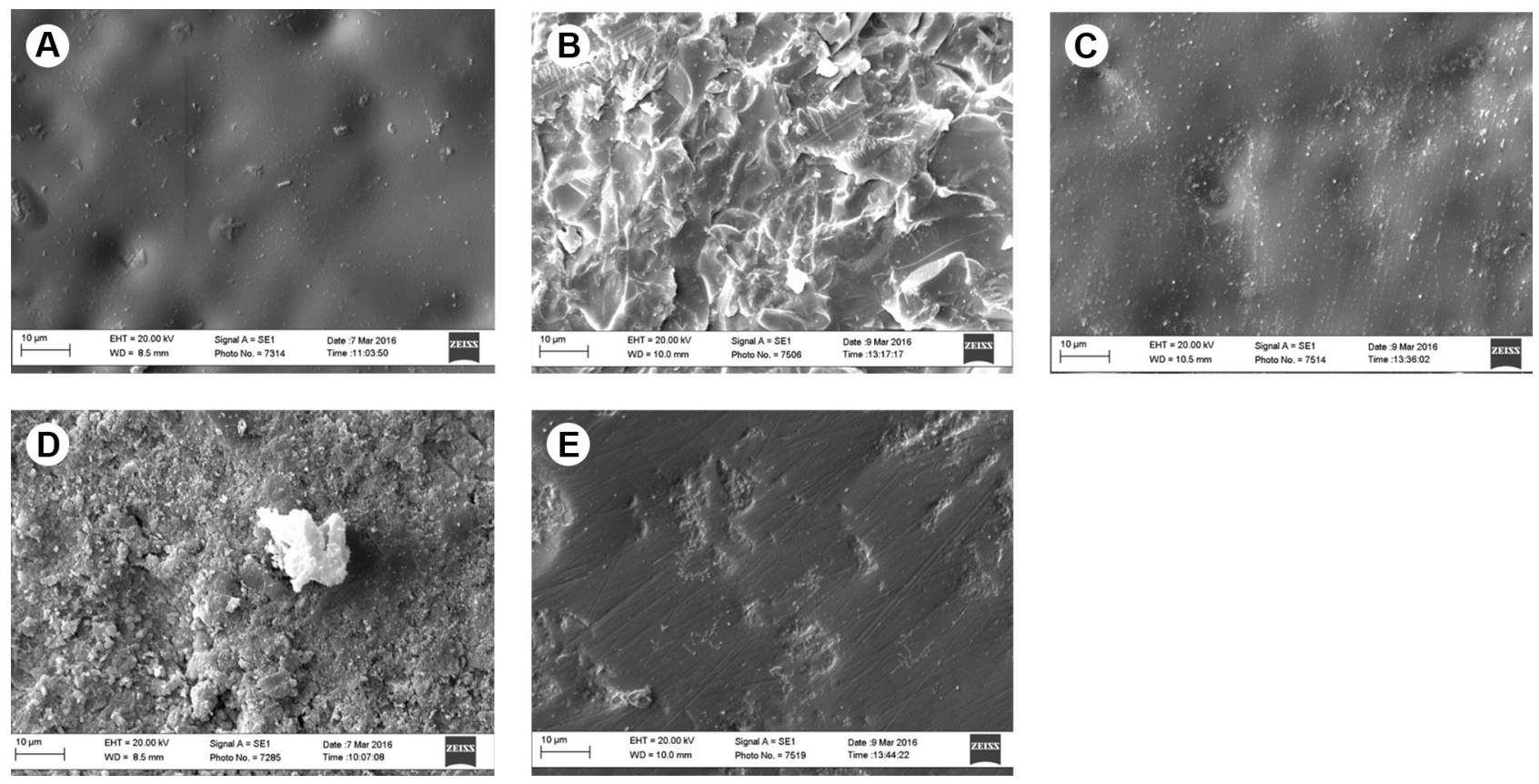

Figure 2. Superficial morphological pattern (100x magnification): A: CT- control group (glaze); B: DA- fine grit diamond bur; C: DG- fine grit diamond bur + new glaze layer; D: DP- fine grit diamond bur + felt disk with fine grit diamond paste; E: DK- fine grit diamond bur + sequential polishing with silicon abrasive instruments, goat hair brush and cotton wheel. 
profilometer and AFM analyses. The DK group showed the most homogeneous and smooth surface, with few bubbles and flaws being detected (16). Groups DG and CT presented similar surface characteristics to DK, with no relevant irregularities, but showing few bubbles due to the glazing process. DA group also showed the worst surface characteristics on the SEM images followed by the DP group, which presented several surfaces irregularities, grooves and gaps. The use of the polishing diamond paste after the adjustment procedures using diamond burs was not effective in regularizing the ceramic surface, since the diamond particles were not sufficient to produce a smooth surface, as shown by the SEM images. As expected, DA group showed the highest irregularities in the surface which were caused by the abrasion of the diamond burs following adjustments without subsequent polishing. Again, this finding highlights the importance of performing chairside polishing of ceramic restorations after adjustments using diamond burs (19). Additionally, maybe the use of a polishing paste after the finishing/polishing protocol from DK group could provide a slight improvement in the surface roughness when used, but, it was not effective in removing the irregularities when used isolated, as shown in the SEM images from DP group.

The spectrophotometric reflectance evaluated the surface gloss of the pressable ceramic. The surface gloss represent the amount of specular (mirror-like) reflection from a surface $(19,20)$. Therefore, gloss is affected by the index of refraction of a material (measure of the ability of a material to change the velocity and direction of incident light upon contact with its surface) and the topography of its surface (20). In this study, the highest surface gloss value was observed for DK (3364.7 \pm 5.893$)$, followed by DG (3360.8 \pm 5.336$)$ and CT (3356.8 \pm 3455$)$. DK group presented satisfactory gloss because the protocol was finished with goat hairbrush and cotton wheel, what lead to satisfactory brightness. These results support the idea that surface roughness may affect the general appearance of dental ceramics (21), since surface gloss and fluorescence can modify the color composition (hue, chroma and value) of teeth and restorative materials (22). If the object has a smooth surface, the light is reflected in a narrow cone centered about the angle of reflectance. In contrast, an increasingly roughened surface would reflect individual segments of the specular beam at slightly different angles (23), reducing the resulting surface gloss.

No significant differences were verified between the biaxial flexural strength among the experimental groups tested in this study. The intensity of the surface roughness changes generated by the finishing-polishing procedures was probably too small to produce any deleterious effects on the biaxial flexural strength, since the polishing procedures tested were not detrimental to the mechanical properties of the pressable ceramic. Probably the surface irregularities and defects observed in the glaze layer were reduced after finishing and polishing, what consequently caused a numerical increase in the biaxial flexural strength of the ceramic specimens, despite non-significant differences were verified for the groups (17). This result can be explained because the flexural strength of dental ceramics depends more on the intrinsic factors such as microstructural stresses and bulk defects than on surface roughness (24). The quality of ceramic and the sintering protocol used can be responsible for deeper changes in the characteristics of the ceramic, irrespective of the finishing/polishing protocol (3). As the specimens used in this study were produced with a pressed ceramic material, this resulted in more homogeneous ceramic discs, what also may help to explain the results observed in the biaxial flexural strength test. Moreover, leucite containing ceramics have higher strength since the grains within the glass reduce flaws (4). Additionally, the biaxial flexural strength values found for the specimens of all experimental groups in the present study are within the values reported for pressable fluorapatite glass ceramic in the current literature (4).

The physicomechanical properties of dental ceramics are closely related to the polishing capacity of these materials. After the rupture of the glaze layer by performing adjustments in the restoration, the best option for finishing and polishing ceramics will depend on the type of material used (25). Thus, the protocol for finishing and polishing dental ceramics must be adjusted to each material correctly. Based on the results of this study, it was observed that the polishing protocols had no effect on the biaxial flexural strength of the pressable ceramic tested. However, the sequential finishing-polishing protocol employed with silicon carbide abrasive instruments (coarse, medium, and fine grit), goat hair brush and cotton wheel systems was effective in reducing the surface roughness, producing a smoother surface with higher gloss in comparison with the other protocols used. Therefore, chairside sequential systems can be a good alternative for clinical finishing-polishing of the adjusted surfaces in pressable ceramic.

Based on the results of this study, it may be concluded that: 1) glazed and polished surfaces produced statistically similar biaxial flexural strength for the pressable ceramic used (IPS e.max ZirPress, Ivoclar Vivadent), irrespective of the polishing protocols tested. 2) Performing adjustments without polishing the surfaces affected the surface roughness of the ceramic material; however, when polishing was performed with sequential finishing-polishing protocol (DK) using silicon carbide abrasive instruments (coarse, medium, and fine grit), goat hair brush and cotton wheel, a significant reduction was observed for the surface 
roughness. 3) Glazing (CT), reglazing (DG) or sequential polishing (DK) are effective for increasing surface gloss, resulting in smoother surfaces. A clinical implication of the present study is that chairside sequential systems can be a good alternative for clinical finishing-polishing of adjusted surfaces for the pressable ceramic tested.

\section{Resumo}

0 objetivo deste estudo foi avaliar o efeito de diferentes protocolos de acabamento e polimento na rugosidade da superfície, brilho, resistência à flexão biaxial e morfologia de cerâmica prensada. Trinta discos de cerâmica $(12 \times 1 \mathrm{~mm})$ foram produzidos e divididos em cinco grupos $(n=6)$ : CT- controle (glaze); DA- ponta diamantada de granulação fina; DG: DA + nova camada de glaze; DP: DA + disco de feltro com pasta de diamante de granulo fino; DK: DA + polimento sequencial com instrumentos abrasivos de silício, escova de cabra e roda de algodão. Os espécimes foram analisados quanto à rugosidade da superfície (Ra) sob profilometria e microscopia de força atômica (AFM). 0 brilho foi medido com espectrofotometria e a micromorfologia com microscopia eletrônica de varredura (SEM). A resistência à flexão foi avaliada pelo teste de resistência à flexão biaxial. Os dados foram analisados usando ANOVA um fator e teste post hoc de Tukey $(\alpha=0,05)$. DK mostrou mais baixos valores de rugosidade da superfície e DA apresentou o maior na análise do perfilômetro. Não foram observadas diferenças significativas no AFM para os grupos CT, DG e DK, que apresentaram a menor rugosidade de superfície; DA e DP apresentaram os maiores valores Ra. 0 DA, DP e CT mostraram valores de brilho superficial mais baixos, e a reflectância foi significativamente diferente da observada para os grupos DK e DG. A análise de SEM revelou $\vec{z}$ a superfície mais homogênea para o grupo DK, seguido de grupos DG e CT; Os grupos DA e DP exibiram graus variáveis de irregularidades da superfície. Não foram observadas diferenças significativas entre os grupos quanto à resistência à flexão biaxial. 0 protocolo de polimento utilizado no grupo $\therefore$ DK pode ser uma boa alternativa para o acabamento em consultório das superfícies de cerâmicas prensadas após ajustes.

\section{Acknowledgements}

This research was partially supported by the Minas Gerais State Agency for Research and Development (FAPEMIG - Grant 2015-0528).

\section{References}

1. Ozarslan MM, Buyukkaplan US, Barutcigil C, Arslan M, Turker N, Barutcigil K. Effects of different surface finishing procedures on the change in surface roughness and color of a polymer infiltrated ceramic network material. J Adv Prosthodont 2016;8:16-20.

2. Sethi $S$, Kakade $D$, Jambhekar $S$, Jain $V$. An in vitro investigation to compare the surface roughness of auto glazed, reglazed and chair side polished surfaces of Ivoclar and Vita feldspathic porcelain. J Indian Prosthodont Soc 2013;13:478-485.

3. Boaventura JM, Nishida R, Elossais AA, Lima DM, Reis JM, Campos EA, et al. Effect finishing and polishing procedures on the surface roughness of IPS Empress 2 ceramic. Acta Odontol Scand 2013;71:438-443.

4. Choi JE, Waddell JN, Torr B, Swain MV. Pressed ceramics onto zirconia. Part 1: Comparison of crystalline phases present, adhesion to a zirconia system and flexural strength. Dent Mater 2011;27:1204-1212.

5. Brentel AS, Kantorski KZ, Valandro LF, Fucio SB, Puppin-Rontani RM, Bottino MA. Confocal laser microscopic analysis of biofilm on newer feldspar ceramic. Oper Dent 2011;36:43-51.
6. Fasbinder DJ, Neiva GF. Surface evaluation of polishing techniques for new resilient CAD/CAM restorative materials. J Esthet Restor Dent 2016;28:56-66.

7. Wang $H_{1}$ Xiong $F$, Zhenhua $L$. Influence of varied surface texture of dentin porcelain on optical properties of porcelain specimens. J Prosthet Dent 2011;105:242-248.

8. Kim KH, Loch C, Waddell JN, Tompkins G, Schwass D. Surface Characteristics and Biofilm Development on Selected Dental Ceramic Materials. Int J Dent 2017; 2017:7627945.

9. Jagger $D C$, Harrison A. An in vitro investigation into the wear effects of unglazed, glazed, and polished porcelain on human enamel. J Prosthet Dent 1994;72:320-323.

10. Fischer $H$, Schafer M, Marx R. Effect of surface roughness on flexural strength of veneer ceramics. J Dent Res 2003;82:972-975.

11. Silva TM, Salvia AC, Carvalho RF, Silva EG, Pagani C. Effects of different polishing protocols on lithium disilicate ceramics. Braz Dent J 2015;26:478-483.

12. International Organization for Standardization. ISO 6872:2015. Dentistry-ceramic materials. Geneva, Switzerland: International Organization for Standardization; 2015

13. Kursoglu P, Karagoz Motro PF, Kazazoglu E. Correlation of surface texture with the stainability of ceramics. J Prosthet Dent 2014;112:306313.

14. Tholt de Vasconcellos B, Miranda-Junior WG, Prioli R, Thompson $J$, Oda M. Surface roughness in ceramics with different finishing techniques using atomic force microscope and profilometer. Oper Dent 2006;31:442-449.

15. Whitehead SA, Shearer AC, Watts DC, Wilson NH. Comparison of two stylus methods for measuring surface texture. Dent Mater 1999;15:7986.

16. Sarac D, Sarac YS, Yuzbasioglu E, Bal S. The effects of porcelain polishing systems on the color and surface texture of feldspathic porcelain. J Prosthet Dent 2006;96:122-128.

17. Ruschel VC, Maia HP, Lopes GC. Influence of external and internal surface roughness modifications on ceramic flexural strength. J Prosthet Dent 2014;112:903-908.

18. Bottino $M C$, Valandro LF, Kantorski $K Z$, Bressiani JC, Bottino MA. Polishing methods of an alumina-reinforced feldspar ceramic. Braz Dent J 2006;17:285-289.

19. de Jager N, Feilzer AJ, Davidson CL. The influence of surface roughness on porcelain strength. Dent Mater 2000;16:381-388.

20. Sulaiman TA, Abdulmajeed AA, Donovan TE, Ritter AV, Vallittu PK, Narhi TO, et al. Optical properties and light irradiance of monolithic zirconia at variable thicknesses. Dent Mater 2015;31:1180-1187.

21. Yap AU. Color attributes and accuracy of Vita-based manufacturers' shade guides. Oper Dent 1998;23:266-271.

22. Obregon A, Goodkind RJ, Schwabacher WB. Effects of opaque and porcelain surface texture on the color of ceramometal restorations. J Prosthet Dent 1981;46:330-340.

23. Lee YK, Lim BS, Kim CW. Effect of surface conditions on the color of dental resin composites. J Biomed Mater Res 2002;63:657-663.

24. Flury $S$, Peutzfeldt A, Lussi A. Influence of surface roughness on mechanical properties of two computer-aided design/computer-aided manufacturing (CAD/CAM) ceramic materials. Oper Dent 2012;37:617624.

25. al-Hiyasat AS, Saunders WP, Sharkey SW, Smith GM, Gilmour WH. The abrasive effect of glazed, unglazed, and polished porcelain on the wear of human enamel, and the influence of carbonated soft drinks on the rate of wear. Int J Prosthodont 1997;10:269-282.

Received June 30, 2018 Accepted October 11, 2018 